\title{
Cost comparisons of available brands of insulin glargine preparations
}

\author{
Vikram Anant Rajadnya ${ }^{1}$, Diya Amol More ${ }^{2 *}$
}

${ }^{1}$ Department of Pharmacology, D. Y. Patil Medical College, Kolhapur, Maharashtra, India

${ }^{2}$ D. Y. Patil Medical College, Kolhapur, Maharashtra, India

Received: 21 May 2021

Revised: 14 June 2021

Accepted: 15 June 2021

\section{*Correspondence:}

Dr. Diya Amol More,

Email: diyamore2000@gmail.com

Copyright: (C) the author(s), publisher and licensee Medip Academy. This is an open-access article distributed under the terms of the Creative Commons Attribution Non-Commercial License, which permits unrestricted non-commercial use, distribution, and reproduction in any medium, provided the original work is properly cited.

\begin{abstract}
Background: The objective was to study the annual cost of each of the four important brands of insulin glargine available in India and to study the comparative annual cost of all the four brands.

Methods: Four most commonly prescribed brands of insulin glargine vials were selected for cost comparisons. The daily as well as annual cost of prescription of insulin glargine vials based on once daily use was worked out directly as well as in percentages and presented in the form of table and bar diagrams.

Results: After careful analysis of the data it was found that the costliest brand, brand D is more than two times costlier than the cheapest brand, brand B and thus the brand preparation selection, can lead to huge difference in annual cost burden to the patient.

Conclusions: This significant cost difference between costliest and cheapest brands of insulin glargine vials assumes even further importance since majority of the diabetics need to bear the cost of multiple drugs prescribed to them, on their own. Thus it rather becomes a duty of the prescribing health care provider to prescribe those medicines which are cost effective to his/her patients.
\end{abstract}

Keywords: Insulin glargine vials 100 units/ml, Cost, Annual cost

\section{INTRODUCTION}

Diabetes is a metabolic disorder included in chronic NCD (chronic non communicable diseases). Thus its management is also long term, mostly lifelong. ${ }^{1}$ Diabetes mellitus is classified into various subtypes. ${ }^{2}$ The management includes lifestyle modification including yogic practices, stress reduction, medical nutrition and diet treatment and physical activity. The pharmacological management includes insulin and oral medications. ${ }^{3}$ Insulin glargine belonging to the insulin group of drugs, is one of the important baseline insulin sub types used in IDDM (insulin dependent diabetes mellitus), certain select cases of NIDDM (non-insulin dependent diabetes mellitus) and certain specific clinical situations in diabetes management. ${ }^{4,5}$ It is used as a baseline insulin preparation which covers the daily baseline requirement of insulin in the patient. It is used along with bolus insulin preparations or oral drugs. It is injected as a single daily injection in a dose of 0.2 units/kilogram of body weight per day 6 . Multiple brands of insulin glargine are available in India. As mentioned above the treatment of diabetes is long term. Thus insulin glargine prescription might be required for years together and lifelong for a large percent amongst selected patients. With long term or lifelong treatment, comes one very important aspect of drug prescription, the ongoing cost of the medication. Thus the prescribing healthcare provider must take into consideration the cost of the medicine. A number of brand preparations of insulin glargine are available in the Indian market. The authors undertook a comparative cost study of a few selected 
preparations of insulin glargine available, in only vial forms, as described in detail in methods.

\section{METHODS}

The present study was conducted in India. Four brands of insulin glargine vials 100 units per millilitre were selected for the study. This was based on the information about the price of these brand preparations available on the internet. ${ }^{7}$ Based on this the price of $1 \mathrm{ml}$ of insulin glargine available only in vial forms of these four brands were noted. These prices were the MRP (maximum retail price) available to the patient in turn the price of each insulin unit of these brand preparations were calculated for each of the four brands.

Each brand was named by a code alphabet from A to D to follow confidentiality.

\section{Inclusion criteria}

Only insulin glargine 100 units per millilitre vial preparations were selected.

\section{Exclusion criteria}

The other preparations such as insulin glargine 300 units per millilitre preparations, the pens, disposable pen preparations were not considered for this study.

From the price of the available vials, the price of one millilitre of the insulin glargine preparation was calculated for each selected brand. The price of each insulin unit was calculated in turn for each brand preparation. Considering once daily dosing of 0.2 units per $\mathrm{kg}$ body weight per day was calculated. The body weight for these calculations was taken 65 kilogram. This is the average weight of the young Indian male. ${ }^{8}$ And it is considered as standard weight for any calculations based on body weight in Indian people. This is the daily cost of insulin glargine to the patient. The annual cost of each preparation was also worked out from the daily cost to the patient. Further this data was also converted in percentage form considering the cheapest brand price that is of brand B as $100 \%$ and that for other brands were also calculated accordingly. The data was presented in tabular form and bar diagram form.

\section{Statistical analysis}

No extensive statistical tools were required for our study. Only simple multiplications, divisions, calculation of percentages was used to analyse the data.

\section{RESULTS}

The price of insulin glargine per millilitre and per unit of each brand is presented in Table 1. The price of the insulin glargine indicating daily cost to the patient and the annual cost of the prescription is presented in Table 2 and Figure 1. Accordingly, brand B is the cheapest while brand D is the costliest one. Cost of the two remaining brands fall In between these two brands. The brand $\mathrm{B}$ is more than two times or more than $200 \%$ costlier than brand B.

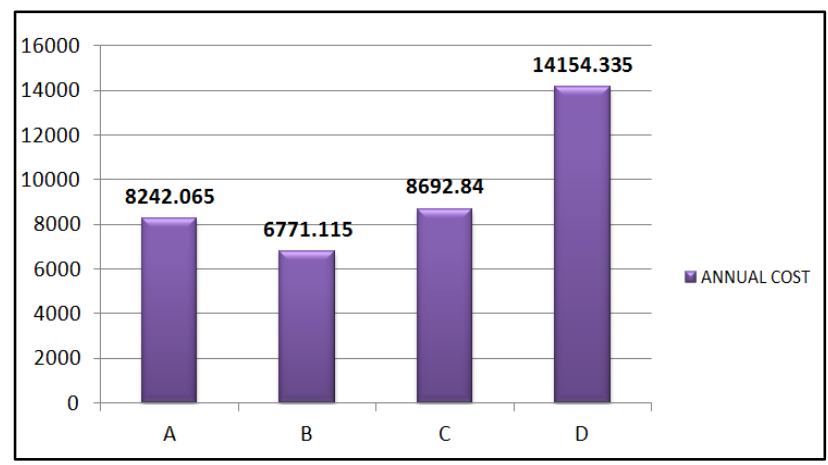

Figure 1: Annual cost of insulin glargine 100 units/ml based on once daily dosing.

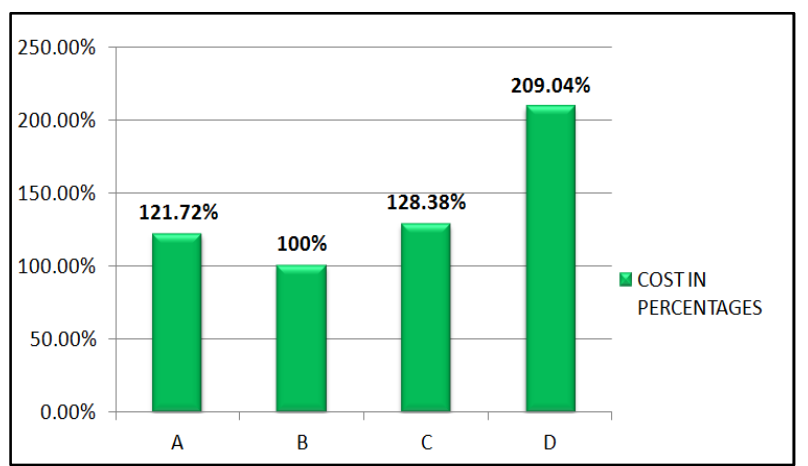

Figure 2: Cost comparison between brands of insulin glargine $100 \mathrm{units} / \mathrm{ml}$ in percentages.

Table 1: Cost of insulin glargine per $\mathrm{ml}$ and per unit.

\begin{tabular}{|lll|}
\hline Brand code name & Price per $\mathrm{ml}$ (in ₹) & Price per unit (in ₹) \\
\hline A & 173.7 & 1.737 \\
\hline B & 142.7 & 1.427 \\
\hline C & 183.2 & 1.832 \\
\hline D & 298.3 & 2.983 \\
\hline
\end{tabular}

Table 2 shows daily and annual cost of various brands of insulin glargine taking into consideration once daily dosing of 0.2 units per $\mathrm{kg}$ body weight per day in a 65 kilogram patient. The annual cost of brand D (14154.335 ₹ annually) 
which is the costliest amongst all the brands, is more than two times that of the cheapest brand, brand B (6771.115 ₹ annually). The cost of the remaining brand preparation falls in between these two brands as far as daily and annual cost is concerned. Only insulin glargine 100 units per millilitre in the vial forms are considered.

Table 2: The daily as well as the annual cost of insulin glargine 100 units/ml based on once daily dosing.

\begin{tabular}{|lll|}
\hline Brand code name & Daily cost with once daily dosing (13 units per dose) & Annual cost with once daily dosing \\
\hline A & 22.581 & 8242.065 \\
\hline B & 18.551 & 6771.115 \\
\hline C & 23.816 & 8692.84 \\
\hline D & 38.779 & 14154.335 \\
\hline
\end{tabular}

Table 3: Cost comparisons between brands of insulin glargine in percentages.

\begin{tabular}{|ll|}
\hline Brand code name & Annual cost comparison in percentages* \\
\hline A & 121.72 \\
\hline B & 100 \\
\hline C & 128.38 \\
\hline D & 209.04 \\
\hline
\end{tabular}

*cheapest brand that is brand $\mathrm{B}$ is taken as $100 \%$.

Table 3 depicts the annual coasts of all brands of in the form percentages. Considering cheapest insulin glargine brand preparations that is brand B as $100 \%$. Thus it was observed that the cost of costliest brand that is brand $\mathrm{D}$ is $209.04 \%$ that of the cheapest brand (brand B).

Figure 1 The bar diagram showing the annual cost of four various brands preparations considering once daily dosing of 0.2 units per $\mathrm{kg}$ body weight per day in a 65 kilogram patient.

Figure 2 presents the annual of all the three brands preparations in the form percentages considering cheapest brand that is brand as $100 \%$. Thus it was observed that the cost of costliest brand that is brand D was more the two times higher than the cheapest brand (brand B).

\section{DISCUSSION}

While prescribing any medication the physician considers many factors. ${ }^{9}$ One important factor is considering the cost of the medicine to the patient. Considering the cost assumes more importance when the medication might be required long term or even lifelong. Thus insulin glargine as used in IDDM, selected patients of NIDDM in carefully chosen patients is required long term perhaps lifelong in majority of the patients. India is a country where great economic disparity exists. The poor patients definitely need to focus a lot on the cost factor. Indian government has some regulations in place as far as the cost of medicines is concerned. But in spite of this, a large difference in cost may exist between various brands of the same drug. The present study was undertaken to study the cost disparity between certain brands of insulin glargine. Four brands of insulin glargine in vial form which are available in India where the study was conducted. As mentioned above the costs of medication per day and the annual cost of each brand were compared. It was found that there is more than two times cost variation between the cheapest and the costliest brands, $6771.115 ₹$ and 14154.335 ₹ of annual cost of brand $\mathrm{B}$ and brand $\mathrm{D}$, respectively. Considering the findings of the present study, we recommended that the prescribing healthcare provider should include cost considerations while prescribing insulin glargine to his/her patients. Selection of a brand preparation is a personal choice of the physician. This choice is in turn based on many factors such as availability of that brand preparation, physicians experience with a particular brand preparations and certain other factors. ${ }^{9}$ Last but not the least factor is the cost. This factor assumes even more importance in a country like India where a large socioeconomic difference was seen. Another factor was, that majority of the Indian patients pay the costs of the medications from their own pockets, since medical insurance is still accepted by very few percent of our population. ${ }^{10}$ Still another factor to consider is that many of the diabetic patients also likely suffer from other co-morbidities. And thus they might also be prescribed amongst one or more of the other antidiabetics such as sulfonylureas, as well as antiplatelets, hypolipidemics, antihypertensives. This further added to the annual cost of the medications and thus patients are more likely to be highly sensitive about the drug cost factor. Thus it rather becomes a duty of the prescribing physician or healthcare provider to prescribe those medicines which are cost effective to his/her patients. In addition, discussion about the cost burden with individual patient must be a routine practice.

\section{Limitation}

There were no obvious shortcomings to our study. 


\section{CONCLUSION}

Cost of medications in patients with diabetes should be a major factor guiding the prescription practices of the healthcare providers. This is especially relevant in a country like India where the patients are highly price sensitive, considering that majority of the patients are not covered by medical insurance and the likelihood of multiple drugs being prescribed to the diabetic patients especially when these also carry co morbidities.

Funding: No funding sources

Conflict of interest: None declared

Ethical approval: The study was approved by the Institutional Ethics Committee

\section{REFERENCES}

1. Reitzle L, Schmidt C, Scheidt-Nave C, Ziese T. An international comparison of non-communicable disease reporting: the case of diabetes mellitus. J Health Monitor. 2019;4(2):64.

2. American Diabetes Association. Classification and diagnosis of diabetes. Diabetes Care. 2015;38(1):8-16.

3. Drugs.com. Fact sheet: Diabetes Mellitus, 2020. Available at: https://www.drugs.com/healthguide/diabetes-mellitus.html. Accessed on 5 May 2021.

4. Candido R, Wyne K, Romoli E. A review of basal bolus therapy using insulin glargine and insulin Lispro in the management of diabetes mellitus. Diabetes Ther. 2018;9(3):927-49.
5. Gu T, Hong T, Zhang P, Tang S, Bi Y, Lu H, et al. Insulin glargine combined with oral antidiabetic drugs for asians with type 2 diabetes mellitus: a pooled analysis to identify predictors of dose and treatment response. Diabetes Ther. 2018;9(2):771-87.

6. Drugs.com. Fact sheet: Insulin glargine dosages, 2020. Available at: https://www.drugs.com/ dosage/insulin-glargine.html. Available on 5 May 2021.

7. Netmeds.com. Fact sheet: Insulin glargine $100 \mathrm{U} / \mathrm{ml}$, 2020. Available at: https://m.netmeds.com/ generics/insulin-glargine-100iu. Accessed on 5 May 2021.

8. National institute of Nutrition (NIN), Indian Council of medical research (ICMR); A Reports of The Expert Group 2020, Nutrient requirements For Indians; 2020 ; page 1. Availabel at: https://www.nin.res.in/. Accessed on 20 May 2021.

9. Sharifnia SHA, Mohammadzadeh M, Arzani G, Salamzadeh J, Abolfazli SA, Zali A, et al. Main factors affecting physicians prescribing decisions, the Iranian experience. Iran J Pharm Res. 2018;17(3):1105-15.

10. Shijit VP, Sekher TV. Who gets health insurance coverage in India? New findings from nationwide surveys. XXVII IUSSP Int Populat Confer Busan. Available at: https://iussp.org/. Accessed on 20 May 2021.

Cite this article as: Rajadnya VA, More DA. Cost comparisons of available brands of insulin glargine preparations. Int J Basic Clin Pharmacol 2021;10:830-3. 